\title{
Biochemical and Immunological Properties of a Viral Hybrid Particle Expressing the Plasmodium vivax Merozoite Surface Protein 1 C-terminal Region
}

\author{
Gerhard Wunderlich and Hernando A. del Portillo \\ Departamento de Parasitologia, Instituto Ciências Biomédicas II, Universidade de \\ São Paulo, São Paulo-SP, Brazil \\ Accepted November 22, 1999.
}

\begin{abstract}
Background: Mammalian cells expressing the small hepatitis B virus surface protein (HBs) secrete highly immunogenic $20 \mathrm{~nm}$ lipoprotein particles. Previous studies demonstrated that the fusion of foreign sequences into certain regions of HBs leads to chimeric particles carrying epitopes for the foreign peptide, as well as for HBs. The present study investigates immunologic and biochemical properties of the fusion of the C-terminal region of the merozoite surface 1 protein of $P$. vivax, the most widely distributed human malaria parasite, and HBs (PvMSP1 19 -HBs).

Materials and Methods: COS7 cells were transfected with a plasmid coding for PvMSP1 19 -HBs. The hybrid products were analyzed by density gradient centrifugation and electron microscopy or de-
\end{abstract}

tected by metabolic labeling and immunoprecipitation with anti-HBs and patient-derived anti-P. vivax serum. Mice were immunized with the vector and the antibody response was checked by ELISA.

Results: The fusion PvMSP1 $\mathrm{P}_{19}$-HBs formed particles of 20-45 nm size, which were secreted from COS7 cells. The particles were immunoprecipitable with anti-HBs and serum of different $P$. vivax-positive individuals. Immunization of mice with the construct as a genetic vaccine showed that antibodies were raised mostly against the $\mathrm{PvMSP}_{19}$ domain and recognized the native protein.

Conclusion: Due to its biochemical and antigenic properties, the hybrid particle will be useful in future vaccine trials against the asexual blood stages of $P$. vivax as a genetic and/or a proteic subunit candidate.

\section{Introduction}

The C-terminal region of the merozoite surface protein 1 of Plasmodium $\left(\mathrm{MSP}_{19}\right)$ is one of the most solid subunit vaccine candidates against the asexual blood stages of malaria, although its function remains elusive (1). Experiments in rodents, Aotus and Saimiri monkeys, either with the affinity-purified, yeast-, bacteria- or cell culturederived $\mathrm{MSPI}_{19}$, showed protection against blood stage challenge with P. falciparum (2), P. vivax (3), P. cynomolgi (4), and P. yoelii (5). Recently, a phase 1 clinical trial was reported (6). Since protection is mostly antibody-dependent (1),

Address correspondence and reprint requests to: $\mathrm{H}$. A. del Portillo, Departamento de Parasitologia, Instituto Ciências Biomédicas II, Universidade de São Paulo, São Paulo-SP, 05508-900 Brazil. Phone: +55-11-8187209; Fax +55-11-8187417; E-mail: hesporti@lineu.icb.usp.br the correct folding of $\mathrm{MSPl}_{19}$, which contains two interspecies-conserved epidermal growth factor (EGF)-like domains stabilized by 10 cystein residues, was shown to be of crucial importance. Accordingly, a protective monoclonal antibody binds to a reduction-sensitive epitope in the first EGF-like domain of the $P$. yoelii MSPI $_{19}$ (7). In monkey trials, the E. coliproduced $\mathrm{MSP}_{19}$-gluthation-S-adenosyl transferase (GST) fusion failed to confer protection (8), indicating that the natural conformation of P. falciparum $\mathrm{MSP}_{19}$ may not be achievable in the bacterial expression system. To date, only baculovirus-derived peptides are repeatedly protective in monkey trials $(2,4)$. However, the baculovirus expression system cannot be easily scaled up to produce relevant quantities and yeast-expressed $\mathrm{MSP}_{19}$ are not as effective $(3,9)$. 
Attempts to increase the immunogenicity of $\mathrm{MSP}_{19}$ included the fusion to promiscuous T-helper cell epitopes $(3,9)$ or the use of novel adjuvants, nevertheless, none of them are licensed for human use $(10,11)$.

Another way to increase the antigenicity of peptides is the construction of chimeric fusions with the small hepatitis B virus surface protein (HBs). The HBs moiety in this fusion provides, on one hand, widely recognized T-helper cell epitopes (12) and, on the other hand, leads to the formation of subviral particles with increased intrinsic immunogenicity, ideally carrying the fused epitope in high density on its surface. In earlier studies, chimeric fusions of several peptides with HBs were shown to increase the immunogenicity of the fused domains (13-15). Significantly, the most successful (pre-erythrocytic-stage) human malaria vaccine trial ever reported (16) contained large parts of the circumsporozoite protein fused to HBs, forming chimeric subviral particles purifiable from yeast cells (17).

In order to render $\mathrm{MSPl}_{19}$ of the human malaria parasite $P$. vivax $\left(\mathrm{PvMSP}_{19}\right)$ more antigenic as DNA, we previously reported on the construction of a fusion construct of the PvMSP $_{19}$ gene from the Belem strain and the $H B$ sene (18). In this study, we report on biochemical and immunological properties of the hybrid particle composed of PvMSP ${ }_{19}$ and HBs.

\section{Materials and Methods}

\section{Plasmid Constructs}

The plasmid pSV33M- ${ }^{*}$ coding for HBs [subtype adw2 (19)] is a derivate of pSV33H (20), in which a unique BamHI site was introduced in the downstream position of the first EcoRI site and immediately upstream from the HBs ATG initiation codon. The detailed construction of the recombinant plasmid, VXORF-PvMSP $1_{19}$-HBs, encoding the fusion PvMSPI ${ }_{19}$-HBs protein was described elsewhere (18). The plasmid pGEX2TPVMSPI $_{19}$ was created by insertion of the PvMSPl $_{19}$ fragment into pGEX2T (Pharmacia, Uppsala, Sweden) using the $5^{\prime}$ and $3^{\prime}$ primers (forward 5'-ccggatccATGAGCTCCGAGCACAC and reverse 5'-ccgaattcGAGGACAAGCT-TAGGAAG), respectively. The production of recombinant PvMSP $1_{19}$ as a fusion protein with GST was done as previously described (21). All insert sequences were con- firmed by manual, standard dideoxy sequencing. Plasmids used for transfections were purified using the Maxiprep-Qiagen columns according to the manufacturer's instructions (Qiagen, Hilden, Germany). Plasmids were stored at $-20^{\circ} \mathrm{C}$ in $70 \%$ ethanol until use and then diluted to $1 \mathrm{mg} / \mathrm{ml}$ in phosphate-buffered saline (PBS).

\section{COS7 Cell Transfections}

The plasmids pSV33M- ${ }^{*}$ and VXORF$\mathrm{PvMSPl}_{19}$-HBs were transiently transfected in $50 \%$ confluent COS7 cells using the DEAEDextran method as described (20). Metabolic labeling with ${ }^{35} \mathrm{~S}$-Translabel (ICN, Costa Mesa, CA), immunoprecipitation and visualization of synthesized proteins essentially were done as described (20), except that immunoprecipitates were washed only once with PBS. Immunoprecipitations were either carried out using commercially available anti-HBs serum (Dako, Hamburg, Germany) or sera from human patients infected with $P$. vivax, which were positive for anti-MSPI (and blocked before use with the supernatant of mock-transfected COS7 cells). The human sera were obtained from 4 male and 2 female adult patients in the acute phase of vivax malaria before treatment. All donors were infected in the Brazilian Amazon and reported between 2 and 20 previous malaria episodes.

\section{Purification of Samples for Electron Microscopy}

COS7 cells were transfected as above. Instead of labeling the cells, however, whole supernatants containing secreted proteins were centrifuged for $10 \mathrm{~min}$ at $4000 \mathrm{~g}$ and then subjected to CsCl-gradient $(10-40 \% \quad \mathrm{w} / \mathrm{w})$ centrifugation in $10 \mathrm{ml}$-tubes in a Beckman Ti70 rotor $\left(40 \mathrm{hr}, 45.000 \mathrm{rpm}, 16^{\circ} \mathrm{C}\right)$. Particlecontaining fractions were coated to electron microscopy grids for $20 \mathrm{~min}$ and negativestained with $2 \%$ Uranyl acetate for a further 20 min and stored under vacuum until analysis.

\section{Immunization of Balb/C Mice}

Groups of 10 female Balb/C mice (4-6 weeks old) were immunized intramuscularly in both tibialis anterior muscles with the plasmids VXORF- PVMSP1 19 -HBs (6 mice) or VXORF (4 mice, control group). Three immunizations were given in three-week intervals with 100 $\mu \mathrm{g}$ (50 $\mu \mathrm{g}$ per leg) per dose per mouse. Pre-im- 
mune sera and sera from all animals two weeks after the last boost were collected and stored at $20^{\circ} \mathrm{C}$ until use. Two independent trials were performed.

\section{ELISA}

Sera from all mice were analyzed by enzyme linked immuno-sorbant assay (ELISA) (21) to look for the presence of anti-HBs and/or antiPvMSPl $_{19}$ antibodies. Briefly $0.2 \mu \mathrm{g} / \mathrm{well}$ of recombinant PvMSP $1_{19}$-GST or HBs (kindly supplied by N. Granovski, Instituto Butantan, São Paulo, Brazil) was coated to 96-well microtiter plates, washed, blocked with $4 \%$ skimmed milk in PBS, and incubated with antiserum in different serial dilutions in $1 \%$ milk/PBS. After further washings, bound antibodies were detected by incubation with anti-mouse immunoglobulin G (IgG)-peroxydase conjugate (Sigma, St. Louis, MO). After addition of tetramethylbenzidine $/ \mathrm{H}_{2} \mathrm{O}_{2}$ substrate (Kierkegaard \& Perry Laboratories, Gaithersburg, MD) and 15 min incubation, the colorimetric reaction was stopped with $1 \mathrm{M}$ $\mathrm{H}_{3} \mathrm{PO}_{4}$ and the optical density (OD) 450 was determined.

\section{Results}

\section{COS7 Cells Efficiently Secrete a Hybrid Structure Containing $P v M S P 1_{19}$ and HBs Epitopes}

In the first experiment, we determined whether a hybrid PvMSPI 19 -HBs protein was efficiently translated and secreted by COS7 cells. As shown in Figure 1A, after transfection of COS7 cells with pSV33M- ${ }^{*}$ and metabolic labeling, the HBs proteins of 24 and $27 \mathrm{kD}$ (glycosylated variant) could be immunoprecipitated by anti-HBs from cell lysates and culture supernatants (lanes 1 and 2). When COS7 cells were cotransfected with VXORFPvMSP $_{19}$-HBs and pSV33M- ${ }^{*}$, both forms ( $\sim 6 \mathrm{kD}$ and $24 / 27 \mathrm{kD}$, respectively) could be observed in the supernatant of cells by immunoprecipitation with anti-HBs (lane 4). The secretion, however, of either form seemed slightly less efficient than that of cells transfected with a single plasmid. After transfection of cells with VXORF-PvMSP $1_{19}$-HBs, a protein in the supernatant in the expected size of $\sim 46 \mathrm{kD}$ was precipitated by anti-HBs (lane 6). Under these conditions, no signal was seen in mock-transfected cells (lanes 7 and 8).
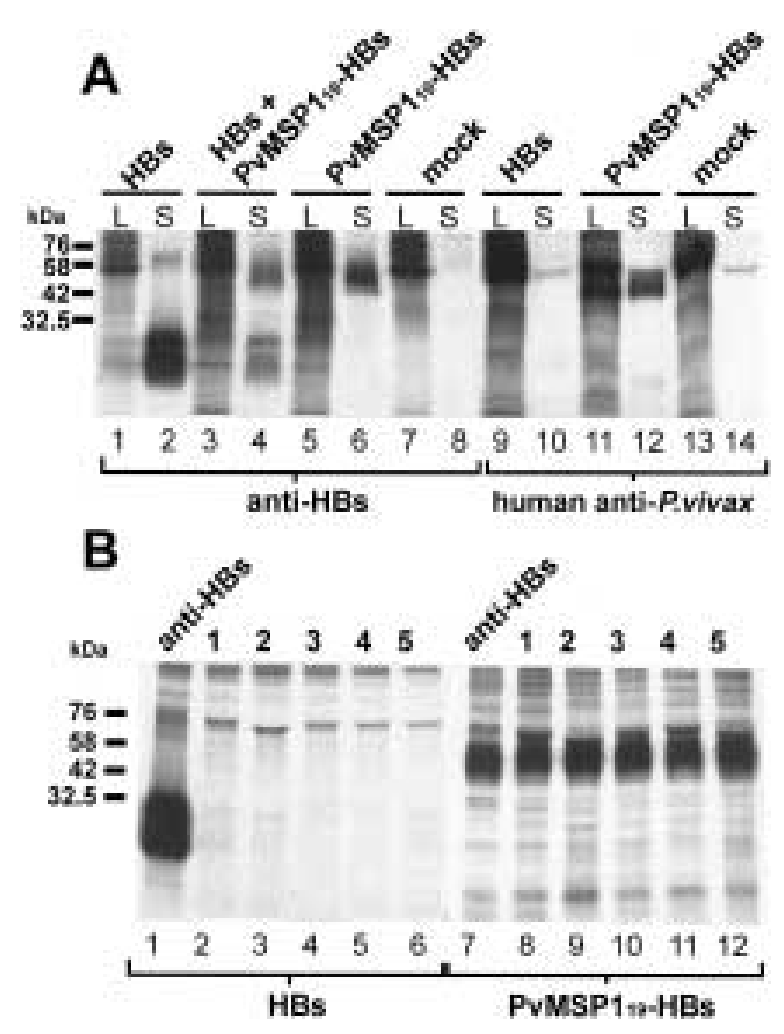

Fig. 1. Expression of $\mathrm{HBs}$ and PVMSP1 ${ }_{19}-\mathrm{HBs}$ in COS7 cells. (A) COS7 cells were transfected with different plasmids and lysates (L) and Supernatants (S) were immunoprecipitated with polyclonal anti-HBs (diluted 1:500) or a presaturated human serum positive for $P$. vivax anti-PvMSPI 19 (diluted $1: 1000)$, but negative for anti-HBs. HBs, transfection with pSV33M- ${ }^{*}$, PvMSP1 $_{19}$-HBs + HBs, Cotransfection with pSV33M- ${ }^{*}$ and VXORF$\mathrm{PVMSP}_{19}$-HBs, PvMSPl 19 -HBs, transfection with VXORF-PVMSP1 19 -HBs, mock: transfection with plasmid pVXORF1. (B) Anti-PvMSPl contained in 5 different human sera recognized the PvMSP1 19 -HBs protein produced in COS7 cells. COS7 cells were transfected with pSV33M- ${ }^{*}$ or VXORF-PvMSP1 $1_{19}$ HBs, pulse labeled and the supernatants immunoprecipitated with the sera from 5 different patients (dilution of each serum $1: 1000$ ). They were analyzed by SDS-PAGE. As a positive control, supernatants were immunoprecipitated with anti-HBs. HBs, small hepatitis B virus surface protein.

When the material produced by transfected and labeled cells was immunoprecipitated with the serum from a $P$. vivax-infected patient blocked previously with mock-transfected unlabeled COS7 culture supernatant, a band of $46 \mathrm{kD}$ could be observed (Fig. 1A, lanes 11 and 12). This band was absent in material from cells transfected with pSV33M- ${ }^{*}$ or mocktransfected cells (lanes 9, 10, 13, 14). As the antiserum previously tested negative for anti-HBs in ELISA and failed to precipitate wildtype 
HBs (lanes 9 and 10), precipitation of the hybrid structure was conferred by the PvMSP1 19 domain (lanes 11 and 12). This confirmed that the PvMSPI 19 portion of the chimeric protein was localized on the particle surface and accessible for precipitating antibodies specific for the natural PvMSPI 19 peptide.

Immune Sera Specifically Recognized PvMSP $1_{19}$ Epitopes Expressed on the Surface of the Secreted Hybrid Protein

We then asked if different sera of individuals infected with $P$. vivax were able to recognize the COS7 cell-expressed PvMSP1 $1_{19}$-HBs construct. Therefore, supernatants of VXORF-PvMSP1 ${ }_{19^{-}}$ HBs or pSV33 $\mathrm{M}^{-*}$ transfected and pulselabeled COS7 cells were immunoprecipitated with sera from 5 different individual $P$. vivax patients containing anti-PvMSP1 ${ }_{19}$ antibodies, but no detectable anti-HBs antibodies. Significantly, all sera precipitated the PvMSP1 ${ }_{19}$-HBs construct, but not HBs, further confirming that the structure displayed PvMSPI ${ }_{19}$ epitopes recognized in natural vivax infections (Fig. 1B, lanes 7-12).

\section{Chimeric Structures Form Particles and Have Slightly Different Densities than Wildtype HBs}

To test if the COS7-expressed PvMSPI 19 -HBs hybrid protein formed particles morphologically, compared with wildtype HBs 20-nm particles, COS7 cells were transfected with pSV33M- ${ }^{*}$ and VXORF-PVMSP $1_{19}$-HBs and metabolically labeled. The resulting supernatants of cells were subjected to $\mathrm{CsCl}$ gradient centrifugation. Fractions were dialyzed and immunoprecipitated with anti-HBs and the precipitate analyzed by SDS-PAGE. The peak fraction of particles containing wildtype HBs had a density of $1.17 \mathrm{~g} / \mathrm{ml}$; whereas, the PvMSP $_{19}$-HBs hybrid structure peaked at $1.22 \mathrm{~g} / \mathrm{ml}$ (data not shown). In a second experiment, secreted material from transfected unlabeled cells was subjected to $\mathrm{CsCl}$ gradient centrifugation as above and the material from the peak fractions $(1.17 \mathrm{~g} / \mathrm{ml}$ and $1.20-1.22 \mathrm{~g} / \mathrm{ml}$, respectively) was examined by electron microscopy. As shown in Fig. 2A, HBs particles of $\sim 22 \mathrm{~nm}$ were found in the supernatant of cells transfected with a plasmid coding for wildtype HBs. Material from cells transfected with the hybrid construct VXORF-PvMSP1 19 -HBs showed particles with differing diameters of

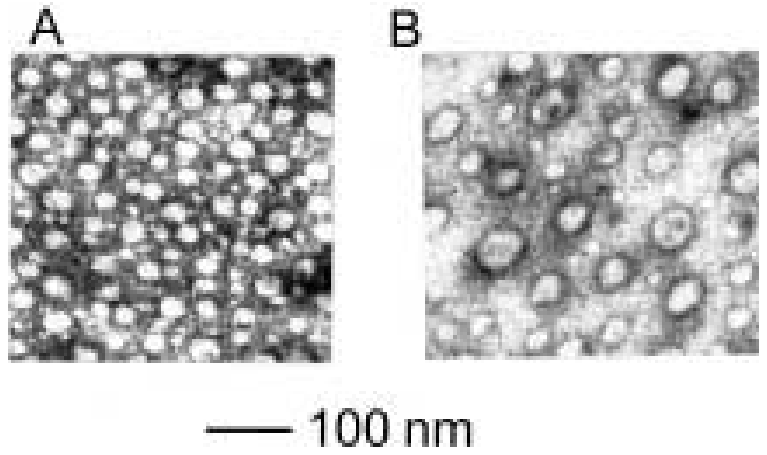

Fig. 2. PvMSP1 19 -HBs forms particles. (A) Electron micrograph showing particles of the supernatant of pSV33M-transfected cells. (B) Micrograph showing hybrid particle structures of differing size $(20-45 \mathrm{~nm})$ derived from supernatant of cells transfected with pVXORF-PVMSP1 19 -HBs. Magnification in A and B was $100.000 \times$.

up to $45 \mathrm{~nm}$ (Fig. 2B). The hybrid particles differed in sizes ranging from 18 to $45 \mathrm{~nm}$ in diameter and this may be due to the voluminous $\mathrm{PvMSP}_{19}$ domain. The average size distribution of particles counted from an entire electron micrograph $(n=163)$ were $4 \% 40-45 \mathrm{~nm}, 30 \%$ $25-40 \mathrm{~nm}$ and $66 \% 18-22 \mathrm{~nm}$. Variations in the morphology of HBs particles also occurred naturally (22). Regardless, these data indicated that, similar to wildtype HBs, PvMSPl 19 -HBs proteins assembled into particle-like structures, which were secreted from expressing cells.

Immunization of Mice with the Recombinant Plasmid VXORF-PvMSP $1_{19}$-HBs Generated Predominantly Antibodies against $P v M S P 1_{19}$

We recently demonstrated that immunization of mice with the recombinant plasmid VXORF- PvMSP1 ${ }_{19}$-HBs elicited antibodies capable of interacting with recombinant $E$. coli PvMSP1 $_{19}$ (18). In order to determine whether these antibodies recognized $\mathrm{PvMSP}_{19}$ and HBs epitopes expressed on the viral chimeric particle, Balb/C mice were immunized with the plasmid VXORF-PvMSP1 $1_{19}$-HBs. After three immunizations, antiserum titers against recombinant PvMSPI $_{19}$ and HBs were determined using ELISA. As shown in Table 1, all mice developed considerable titers for anti-PvMSP1 19 antibodies, but only 2 of 6 or 4 of 6 mice contained low titers for anti-HBs antibodies. In a parallel experiment, COS7 cells were transfected with the plasmids pSV33M-* and VXORF-PvMSPI ${ }_{19}$-HBs, pulse-labeled 
Table 1. Antibody titers in ELISA after immunization of mice with plasmids VXORFl or VXORFPvMSPl 19 -HBs

\begin{tabular}{llccc}
\hline Plasmid & anti-PVMSP1 $_{19}$ & Responders $^{*}$ & anti-HBs & Responders $^{* *}$ \\
\hline VXORF-PVMSP1 $_{19}$-HBs & $1: 12800-1: 51600$ & $6 / 6 / / 6 / 6$ & $1: 200-1: 1000$ & $2 / 6 / / 4 / 6$ \\
VXORF1 & $<1: 100$ & $0 / 0 / / 4 / 4$ & $<1: 50$ & $0 / 0 / / 4 / 4$
\end{tabular}

${ }^{*},{ }^{* *}$ Responders are defined as $\geqslant 1: 500^{*}$ or $\geqslant 1: 200^{* *}$ in endpoint dilution ELISA. HBs, small hepatitis B virus surface protein

with ${ }^{35}$ S-methionine, and cell lysates and supernatants were immunoprecipitated with pooled sera from mice immunized with VXORF-PvMSP1 $1_{19}$-HBs or commercially available anti-HBs serum. Significantly, the genetic immunization of mice elicited antibodies capable of specifically and predominantly interacting with PvMSPI ${ }_{19}$ epitopes (Fig. 3). Moreover, these results were very similar to those observed with sera from $P$. vivax patients (Fig 1B).

\section{Discussion}

In this study, we describe biochemical and immunological properties of the merozoite surface protein 1 C-terminal region of $P$. vivax $\left(\mathrm{PvMSP}_{19}\right)$, presented as a hepatitis $\mathrm{B}$ virus subviral surface antigen hybrid particle. Transfection of COS7 cells with a recombinant plasmid encoding a fusion PvMSP1 ${ }_{19}$-HBs protein led to the production of subviral chimeric particles of $\sim 18-45 \mathrm{~nm}$ diameter with a peak density of $1.22 \mathrm{~g} / \mathrm{ml}$. Moreover, the hybrid protein was precipitable with sera from naturally infected $P$. vivax patients and with sera from mice genetically immunized with this recombinant plasmid.

von Brunn et al. (15) previously described the generation of a recombinant HBs particle containing central parts of MSP1 of P. falciparum in the vaccinia virus expression system. Thus, a significant part of the HBs loop forming the immunodominant a-epitope of HBsAg was exchanged for sequences of MSPI and the different constructs inserted into the vaccinia virus genome by homologous recombination. After infection of CVI cells, subviral particles that were mostly identical in their biochemical behavior to wildtype HBs particles were observed. In a different report, Gordon and colleagues (17) inserted the C-terminal part of the P. falciparum circumsporozoite (CS) protein, which contains several cysteines, into the $\mathrm{N}$ terminal position of HBs. The authors were able to express the construct in Saccaromyces cerevisae as a hybrid particle only if a certain quantity of wildtype HBs was coexpressed. Apparently, the 189 amino acid containing the CS domain caused sterical problems during the budding process of the nascent particle at the endoplasmic reticulum (ER) membrane and, therefore, needed the "help" of wildtype HBs to pass this compartment.

In our studies, we cloned PvMSP1 19 (containing 10 cysteines) also $\mathrm{N}$-terminal of $\mathrm{HBs}$ and under the control of the cytomegalo virus (CMV) promoter (18). Significantly, even as an episomal vector and in the absence of co-expressing wildtype HBs, transiently transfected COS7 cells were able to produce subviral particles (Fig. 2). This result is probably due to the strong nature of the CMV promoter and to the secretion signal from the human tissue plasminogen activator N-terminal to PvMSP1 $1_{19}$. Both might facilitate the transfer of this domain into the ER lumen, thus, dispensing the necessity for additional wildtype HBs for secretion of the recombinant particle. Regardless, the availability of hybrid particles prompted us to determine whether it exposed PvMSPI ${ }_{19}$ epitopes mimicking natural PvMSP $1_{19}$.

We previously demonstrated that naturally acquired IgG antibodies from $P$. vivax patients specifically and predominantly recognized PvMSPI $_{19}$, as opposed to other regions of the PvMSP1 protein (23). Accordingly, we used sera from individual vivax patients in immunoprecipitation assays and clearly demonstrated that the hybrid PvMSP $1_{19}$-HBs particles exposed epitopes recognized in natural infections (Fig. 1B). We next demonstrated that antibodies elicited by genetic immunization of mice with the recombinant plasmid encoding PvMSPI $_{19}$ could also immunoprecipitate the hybrid viral particles (Fig. 3). Moreover, these 


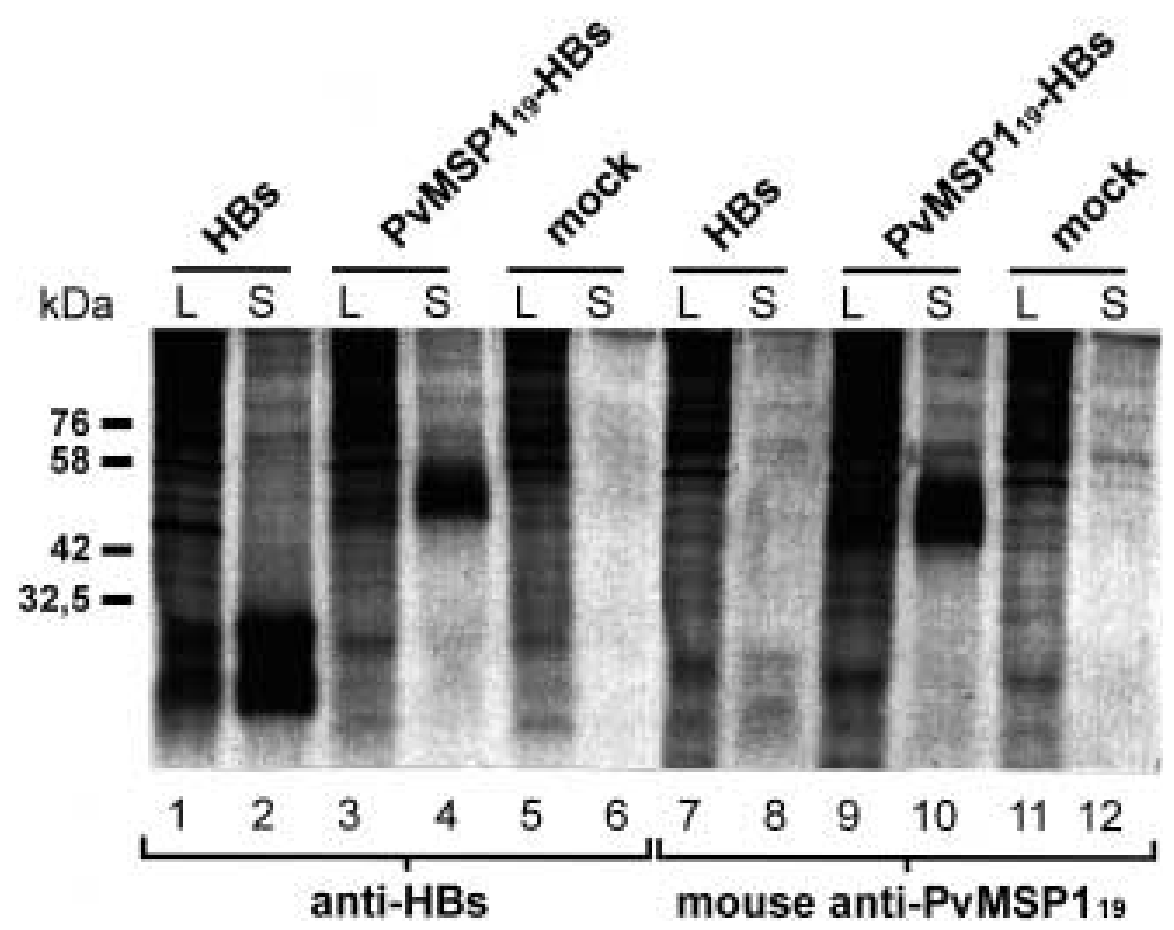

Fig. 3. Sera of VXORF-PVMSP1 19 -HBs immunized mice recognize COS7 cell expressed PVMSP1 $_{19}$-HBs. COS7 cells were transfected with pSV33M-* or VXORF-PvMSP1 ${ }_{19}$-HBs, pulse labeled and cell lysates or supernatants were immunoprecipitated with anti-HBs (lanes 1-6) or pooled sera

antibodies were able to recognize the native protein in immunofluorescence analysis, further suggesting that genetic immunizations with PvMSPI $_{19}$-HBs presented a properly folded PvMSP1 ${ }_{19}$, in spite of its fusion with HBs (data not shown). These results further emphasize the importance of this construct, not only as a proteic subunit vaccine candidate, but also as a DNA vaccine candidate. In addition, the antibody titers against HBs were always lower than against the PvMSP1 19 domain. This could be due to an intrinsically higher immunogenicity of $\mathrm{PvMSPl}_{19}$ than of $\mathrm{HBs}$; alternatively, $\mathrm{PvMSPI}_{19}$ may render the immunodominant a-epitope in HBs partially unaccessible for immunoglobulins. In studies with a form of CS-HBs (24), in which 16 NANP repeats were fused to HBs, a similar result was obtained, even with a smaller peptide size devoid of any conformational structure mediated by disulphide bonds, as was the case in PvMSP1 19 .

Although a significant humoral immunity against PVMSP $1_{19}$ was obtained in the genetic immunizations (Table 1), others correlated pro- derived from VXORF-PvMSP $1_{19}$-HBs-immunized mice (lanes 7-12; dilution of both sera 1:500). HBs transfection with pSV33M- ${ }^{*}, \mathrm{PvMSP}_{19}$-HBs transfection with VXORF-PvMSP $1_{19}$-HBs, mock transfection with plasmid pVXORF1. HBs, small hepatitis B virus surface protein.

tection of rodents against malaria by immunization with $\mathrm{MSPl}_{19}$ to highest antibody titers (25). Still others attributed it to the presence of antibodies directed against a certain reduction-sensitive epitope contained in the first EGF-like domain (7). Studies employing the $\mathrm{MSP}_{19}$-HBs produced in yeast and cell culture for the rodent malaria models $P$. chabaudi and P. yoelii are currently under way to address these issues. Due the fact that there are very few sequence variations in the $P$. vivax $M S P 1_{19}$ gene which are identical in immunologic terms (26), the herein described hybrid particle may be useful as a component in future vaccine trials against blood stage forms of $P$. vivax.

\section{Acknowledgments}

This work was supported by the Fundação de Amparo a Pesquisa do Estado de Sao Paulo (FAPESP), São Paulo, Brazil. We thank Dr. Volker Bruss for the critical reading of the manuscript and Dra. Tania Katzin for help with the electron microscopy. 


\section{References}

1. Miller LH, Good MF, Kaslow DC. (1998) Vaccines against the blood stages of falciparum malaria. Adv. Exp. Med. Biol. 452: 193-205.

2. Chang SP, Case SE, Gosnell WL, et al. (1996) A recombinant baculovirus 42 -kilodalton C-terminal fragment of Plasmodium falciparum merozoite surface protein 1 protects Aotus monkeys against malaria. Infect. Immun. 64: 253-261.

3. Yang CF, Collins WE, Sullivan JS, Kaslow DC, Xiao LH, Lal AA. (1999) Partial protection against Plasmodium vivax blood-stage infection in Saimiri monkeys by immunization with a recombinant C-terminal fragment of merozoite surface protein 1 in block copolymer adjuvant. Infect. Immun. 67: 342-349.

4. Perera KL, Handunnetti SM, Holm I, Longacre S, Mendis K. (1998) Baculovirus merozoite surface protein $1 \mathrm{C}$-terminal recombinant antigens are highly protective in a natural primate model for human Plasmodium vivax malaria. Infect. Immun. 66: 1500-1506.

5. Daly TM, Long CA. (1993) A recombinant 15-kilodalton carboxyl-terminal fragment of Plasmodium yoelii yoelii 17XL merozoite surface protein 1 induces a protective immune response in mice. Infect. Immun. 61: 2462-2467.

6. Keitel WA, Kester KE, Atmar KE, et al. (1999): Phase 1 trial of two recombinant vaccines containing the $19 \mathrm{kd}$ carboxy terminal fragment of Plasmodium falciparum merozoite surface protein 1 (MSPl(19)) and T helper cell epitopes of tetanus toxoid. Vaccine 18: 531-539.

7. Burns Jr. JM, Majarian WR, Young JF, Daly TM, Long CA. (1989) A protective monoclonal antibody recognizes an epitope in the carboxylterminal cysteine-rich domain in the precursor of the major merozoite surface antigen of the rodent malarial parasite, Plasmodium yoelii. J. Immunol. 143: 2670- 2676.

8. Burghaus PA, Wellde BT, Hall T, et al. (1996) Immunization of Aotus nancymai with recombinant C terminus of Plasmodium falciparum merozoite surface protein 1 in liposomes and alum adjuvant does not induce protection against a challenge infection. Infect. Immun. 64: 3614-3619.

9. Herrera, MA, Rosero F, Herrera S, et al. (1992) Protection against malaria in Aotus monkeys immunized with a recombinant blood-stage antigen fused to a universal T-cell epitope: correlation of serum gamma interferon levels with protection. Infect. Immun. 60: 154-158.

10. Chang SP, Nikaido CM, Hashimoto AC, Hashiro CQ, Yokota BT, G. S. Hui. (1994) Regulation of antibody specificity to Plasmodium falciparum merozoite surface protein-1 by adjuvant and MHC haplotype. J. Immunol. 152: 3483-3490.

11. Daly TM, Long CA. (1996) Influence of adju- vants on protection induced by a recombinant fusion protein against malarial infection. Infect. Immun. 64: 2602-2608.

12. Greenstein JL, Schad VC, Goodwin WH, et al. (1992). A universal $T$ cell epitope-containing peptide from hepatitis B surface antigen can enhance antibody specific for HIV gp120. J. Immunol. 148: 3970-3977

13. Delpeyroux, F, Chenciner N, Lim A, Lambert M, Malpiece M, Streeck RE. (1987) Insertions in the hepatitis B surface antigen: Effect on assembly and secretion of the $22 \mathrm{~nm}$-particles from mammalian cells. J. Mol. Biol. 195: 343-350.

14. LeBorgne SM, LeGrand M, Schleef M, et al. (1998). In vivo induction of specific cytotoxic $\mathrm{T}$ lymphocytes in mice and rhesus macaques immunized with DNA vector encoding an HIV epitope fused with hepatitis B surface antigen. Virology 240: 304-315.

15. von Brunn AF, Früh K, Müller H-M, Zentgraf HW, Bujard H. (1991). Epitopes of the human malaria parasite $P$. falciparum carried on the surface of HBsAg particles elicit an immune response against the parasite. Vaccine 9: 477-483.

16. Stoute JA, Slaoui M, Heppner DG, et al. (1997) A preliminary evaluation of a recombinant circumsporozoite protein vaccine against Plasmodium falciparum malaria. N. Engl. J. Med. 336: 86-91.

17. Gordon DM, McGovern TW, Krzych U, et al. (1996) Safety, immunogenicity, and efficacy of a recombinantly produced Plasmodium falciparum circumsporozoite protein-hepatitis B surface antigen subunit vaccine. J. Infect. Dis. 171: 1576-1586.

18. de Oliveira CI, Wunderlich G, Levitus G, et al. (1999) Antigenic properties of the merozoite surface protein 1 gene of Plasmodium vivax. Vaccine 17: 2959-2568.

19. Valenzuela $P$, Rall L, Zaldivar M, Quiroga M, Gray P, Rutter W. (1980) The nucleotide sequence of the hepatitis $B$ virus viral genome and the identification of the major viral genes. ICNUCLA Symp. Mol. Cell Biol. 18: 57-70.

20. Bruss V, Thomssen R. (1994) Mapping a region of the large envelope protein required for hepatitis B virion maturation. J. Virol. 68: 1643-1650.

21. Levitus G, Mertens F, Sperança MA, Camargo LM, Ferreira MU, del Portillo HA. (1994) Characterization of naturally acquired human IgG responses against the $\mathrm{N}$-terminal region of the merozoite surface protein 1 of Plasmodium vivax. Am. J. Trop. Med. Hyg. 51: 68-76.

22. Heermann KH, Goldmann U, Schwartz W, Seyffarth T, Baumgarten H, Gerlich WH. (1984) Large surface proteins of hepatitis B virus containing the pre-s sequence. J. Virol. 52: 396-402.

23. Soares IS, Levitus G, Souza JM, del Portillo HA, Rodrigues MM. (1997) Acquired immune re- 
sponses to the $\mathrm{N}$ - and C-terminal regions of Plasmodium vivax merozoite surface protein 1 in individuals exposed to malaria. Infect. Immun. 65: 1606-1614.

24. Vreden S, Verhave J, Oettinger T, Sauerwein R, Meuwissen J. (1991) Phase I clinical trial of a recombinant malaria vaccine consisting of the circumsporozoite repeat region of Plasmodium falciparum coupled to hepatitis B surface antigen. Am. J. Trop. Med. Hyg. 45: 533-538.
25. Daly TM, Long CA. (1995) Humoral response to a carboxyl-terminal region of the merozoite surface protein-1 plays a predominant role in controlling blood-stage infection in rodent malaria. J. Immunol. 155: 236-243.

26. Soares IS, Barnwell JW, Ferreira MU, et al. (1999) A Plasmodium vivax vaccine candidate displays limited allele polymorphism, which does not restrict recognition by antibodies. Mol. Med. 5: 459-470. 